\title{
Evidence of interaction between fluoxetine and isosorbide dinitrate on neuroleptic-induced catalepsy in mice
}

J.G.P.Pires,

F.C.G. Fonseca,

A.B. Woelffel and

H.A. Futuro-Neto
Departamento de Ciências Fisiológicas, Centro Biomédico, Universidade Federal do Espírito Santo, Vitória, ES, Brasil

\section{Correspondence \\ J.G.P.Pires \\ Departamento de Ciências \\ Fisiológicas \\ Centro Biomédico, UFES \\ Av. Marechal Campos, 1468 \\ 29040-090 Vitória, ES \\ Brasil \\ Fax: 55 (027) 335-7330 \\ E-mail:jgppires@npd.ufes.br \\ J.G.P. Pires and H.A. Futuro-Neto are recipients of CNPq fellowships (Nos. 302073/83-3 and 520279/94- \\ 8).}

Received June 25, 1997 Accepted October 24, 1997

\section{Abstract}

Drugs which influence 5-HTergic mechanisms can modify neuroleptic-induced catalepsy (NC) in rodents, a phenomenon produced by striatal dopamine (DA) receptor blockade. Previous research also suggests a role for endogenous nitric oxide (NO) in the modulation of striatal DAergic neurotransmission; in addition, NO seems to play a role in the 5-HT reuptake mechanism. It is known that clomipramine potentiates $\mathrm{NC}$ in mice, but the reported effects of selective 5-HT reuptake inhibitors (SSRIs) in this model are rather contradictory. We then decided to re-address this issue, investigating the effect of fluoxetine (FX), an SSRI, on NC. In view of the ubiquitous role of NO as a central neuromodulator, we also studied the effect of isosorbide dinitrate (ID), a centrally active NO donor, and how both drugs interact to affect the phenomenon of NC. Catalepsy was induced in male albino mice with haloperidol $(\mathrm{H} ; 1 \mathrm{mg} / \mathrm{kg}$, ip) and measured at 30-min interval by means of a bar test. Drugs (FX, ID and FX + ID) or saline (controls) were injected ip $30 \mathrm{~min}$ before $\mathrm{H}$, with each animal used only once. FX $(5 \mathrm{mg} / \mathrm{kg})$ significantly reduced $\mathrm{NC}$, with maximal attenuation (about 74\%) occurring at $150 \mathrm{~min}$ after $\mathrm{H}$. ID $(5 \mathrm{mg} / \mathrm{kg}$ ) also inhibited NC (150 min: $62 \%$ attenuation). The combined drugs (FX + ID group), however, caused a great potentiation of NC (4.7-fold at its maximum, at $90 \mathrm{~min}$ ). The effect observed with ID is compatible with the hypothesis that NO increases DA release in the striatum. The attenuation of $\mathrm{NC}$ observed with FX may be due to a preferential net effect on the raphe somatodendritic synapse, where inhibitory $5-\mathrm{HT}_{1 \mathrm{~A}}$ autoreceptors are operative. The enhancement of NC caused by combined administration of FX and ID suggests the presence of a pharmacodynamic interaction, whose mechanism, still unclear, may be related to a decrease in striatal DA release.

Administration of typical neuroleptics (e.g., haloperidol, fluphenazine) to rats and mice can induce catalepsy, a state of abnormal postural immobility which is mainly produced by blockade of postsynaptic striatal dopamine $\mathrm{D}_{1}$ and $\mathrm{D}_{2}$ receptors (1). This
Key words

- Fluoxetine

- Isosorbide dinitrate

- Neuroleptic-induced catalepsy

- Nitric oxide

- Serotonin reuptake inhibitors

- Dopaminergic transmission experimental phenomenon is a useful method to evaluate the propensity of antipsychotic agents to exert extrapyramidal side effects, since the motor components of the 'neuroleptic syndrome' in patients (induced by therapeutic doses of neuroleptic drugs) are 
believed to be its clinical correlate. In addition, neuroleptic-induced catalepsy (NC) also continues to be a robust behavioral method for studying central dopaminergic function and its modulation by cholinergic, serotonergic and other neurotransmitter systems (2-7). For instance, we previously reported that clomipramine, a non-selective serotonin (5-HT) reuptake inhibitor, potentiates NC in mice (4). Since there is a tonic 5-HTergic inhibition of dopamine (DA) release $(5,6)$, clomipramine could be acting by increasing this inhibition, thus causing a reduction in DA release, which increases catalepsy. However, the effects of selective 5-HT reuptake inhibitors (SSRIs) on the levels of DA in the striatum are rather contradictory (8). We then decided to re-address this issue, investigating the effect of fluoxetine (FX), an SSRI, on neuroleptic catalepsy. It is also known that endogenous nitric oxide (NO) can act as a neuromodulator on several neurotransmitter systems (see 9), including the 5-HT transport mechanism (10). For this reason, we also studied the effect of isosorbide dinitrate, a therapeutically used NO donor (11), and how both drugs interact to affect the phenomenon of NC.

Experiments were performed on male adult albino mice weighing 26-36 g. Animals were housed individually in Perspex cages $(20 \times 18 \times 13 \mathrm{~cm})$ with free access to

Figure 1 - Effects of fluoxetine (FX), isosorbide dinitrate (ID) and combined FX + ID on neuroleptic-induced catalepsy in mice. Catalepsy was induced by haloperidol $(\mathrm{H} ; 1 \mathrm{mg} / \mathrm{kg}$, ip). The drugs tested, or saline for the control group, were injected ip $30 \mathrm{~min}$ before H. Groups: control (open circles), $5 \mathrm{mg} / \mathrm{kg} \mathrm{FX}$ (filled circles), $5 \mathrm{mg} / \mathrm{kg}$ ID (squares) and $5 \mathrm{mg} / \mathrm{kg} \mathrm{FX}+5$ $\mathrm{mg} / \mathrm{kg}$ ID (inverted triangles). Data are reported as means \pm SEM for 9 mice per group. ${ }^{*} \mathrm{P}<0.05$ and ${ }^{* *} \mathrm{P}<0.01 \mathrm{com}$ pared to control group (Dunnett's $t$-test after ANOVA).

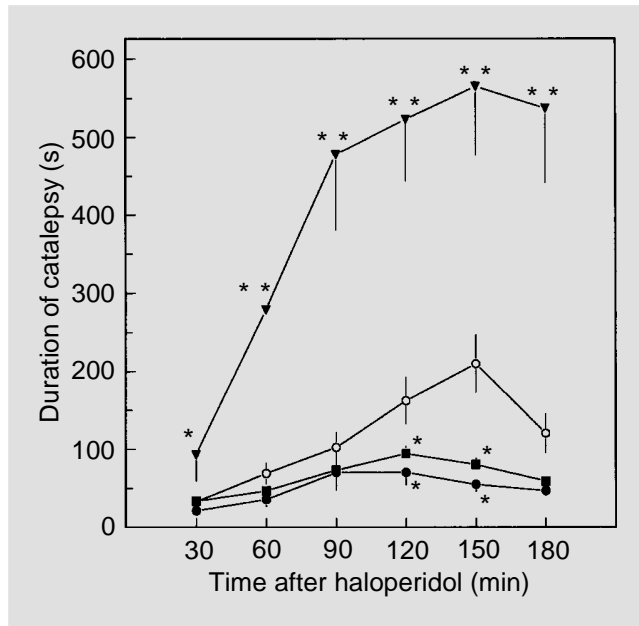

standard pellet food and filtered water, at 23$26^{\circ} \mathrm{C}$. All observations were made between 9:00 and 17:00 $\mathrm{h}$ in a quiet room, with each animal used only once. Catalepsy was induced with haloperidol $(\mathrm{H} ; 1 \mathrm{mg} / \mathrm{kg}, i p)$ and determined at 30-min intervals by means of a standard bar test (7). This dose of $\mathrm{H}$ was chosen to produce a moderate degree of catalepsy so that inhibition or potentiation of catalepsy could be detected $(5,7)$. The phenomenon was measured as the time the animal maintained an imposed position with both front limbs extended and resting on a 3$\mathrm{cm}$ high bar $(0.9 \mathrm{~cm}$ in diameter). The end point of catalepsy was considered to occur when both front paws were removed from the bar or if the animal moved its head in an exploratory manner. The animals were returned to their home cages between determinations. Drugs used were haloperidol (Hal$\mathrm{dol}^{\circledR}$, Janssen, São Paulo, Brazil), fluoxetine (a donation from Eli Lilly, São Paulo, Brazil) and isosorbide dinitrate (Sigma Chemical Co., St. Louis, MO). Haloperidol was diluted from ampoules with saline. Fluoxetine (FX; $5 \mathrm{mg} / \mathrm{kg}$ ) and isosorbide dinitrate (ID; 5 $\mathrm{mg} / \mathrm{kg}$ ), dissolved by sonication in saline, were injected intraperitoneally with a 27.5$\mathrm{G}$ needle, in a volume of $3.2-3.5 \mathrm{ml} / \mathrm{kg}$ body weight, $30 \mathrm{~min}$ before $\mathrm{H}$. The doses were chosen according to those commonly used in the literature. Saline $(0.9 \%, \mathrm{w} / \mathrm{v}, 0.13 \mathrm{ml} /$ animal, $i p$ ) was used as control (CL). Thus, experimental groups were FX, ID, FX + ID and CL. Data are reported as means \pm SEM for 9 mice per group and were analyzed by two-way ANOVA (groups $x$ time) with repeated measures, followed by one-way ANOVA for each time. Dunnett's multiple comparison test was then used to determine statistical differences between CL and other experimental groups, for each time. Differences between means were considered significant when $\mathrm{P}<0.05$.

The results (Figure 1) showed that FX (5 $\mathrm{mg} / \mathrm{kg}$ ) significantly reduced $\mathrm{NC}$, with maximal attenuation (about 74\%) occurring at 
$150 \mathrm{~min}$ after $\mathrm{H}$. The NO donor ID $(5 \mathrm{mg} / \mathrm{kg})$ also inhibited NC (150 min: 62\% attenuation). In both cases the attenuation was shortlasting, since there was no statistically significant difference from the control at 180 min. Surprisingly, combined drugs (FX + ID group) caused an impressive potentiation of catalepsy (4.68-fold at its maximum, at 90 min after H). In six separate experiments, FX or ID alone (up to $15 \mathrm{mg} / \mathrm{kg}$ ip) did not induce a cataleptic state in the mice (data not shown).

It is now accepted that organic nitrates such as glyceryl trinitrate and ID, which act through NO release (11), can easily cross the blood-brain barrier after peripheral administration $(12,13)$. It was also reported that locally produced NO, acting via cGMP, increases 5-HT transport into presynaptic terminals in the brain (10). Taking into account those observations and the existence of a tonic 5-HTergic inhibition of DA release $(5,6)$, we can hypothesize that systemic administration of ID releases NO in the striatum (area involved in the extrapyramidal motor behavior) and that NO, through the increment in 5-HT reuptake, reduces the synaptic concentration of 5-HT, with a subsequent increase of DA release, which obviously reduces NC. Phenomenologically speaking, if an increase in central production of $\mathrm{NO}$ reduces $\mathrm{NC}$, then inhibition of its formation should cause the opposite effect. In fact, it has been recently shown that LNOARG, an inhibitor of NO synthase, induced catalepsy in mice, which was reversed by L-arginine (14).

According to the above model, we should expect that FX, an SSRI drug, should reduce DA release and then potentiate NC. However, we found that FX $(5 \mathrm{mg} / \mathrm{kg})$ attenuated this behavior. Since potentiation of NC with clomipramine in mice was found at a dose of $5 \mathrm{mg} / \mathrm{kg}$ (4), it seems that the 'failure' of FX to increase $\mathrm{NC}$ is not due to an insufficient dose. A possible explanation for this apparent contradiction is that, under the present conditions, FX increased the extracellular levels of 5-HT in the raphe nuclei, which activated somatodendritic 5- $\mathrm{HT}_{1 \mathrm{~A}}$ autoreceptors, causing a reduction in the tonic 5HTergic inhibition of DA release (15). However, since serum levels of haloperidol were not measured before and after the drug treatments, the possibility of a pharmakokinetic interaction among the drugs cannot be discarded.

The potentiation of $\mathrm{NC}$ observed when FX was combined with ID is quite intriguing. To better understand this issue, a crucial question is: how do NO and FX interfere with DA release in the striatum? The answer can be rather complex: it seems that, depending on the experimental conditions, FX (8) and NO (16) can either increase or reduce the levels of DA in the striatum. In the present conditions, we may speculate that, in some way, the release of NO in the striatum (caused by ID) enhanced the inhibitory effect of FX on DA release, surpassing its initial effect on the somatodendritic 5$\mathrm{HT}_{1 \mathrm{~A}}$ autoreceptors. However, the precise mechanism responsible for such interaction remains to be determined. Since both drugs are extensively used in clinical practice, and considering that there is already evidence of parkinsonism and other extrapyramidal side effects following FX in patients (17), the possibility of a clinically relevant interaction between these drugs cannot be discarded and deserves further investigation.

\section{Acknowledgments}

The authors are indebted to Ms. Sara R. Silva (UFES, Vitória) for skilled technical assistance. 


\section{References}

1. Sanberg PR (1980). Haloperidol-induced catalepsy is mediated by postsynaptic dopamine receptors. Nature, 284: 472-473.

2. Vidali M \& Fregnan GB (1979). Effect of different CNS-active drugs on the catalepsy induced by neuroleptics. Current Therapeutic Research, 25: 544-556.

3. Arnt J, Hyttel J \& Bach-Lauritsen T (1986). Further studies of the mechanism behind scopolamine-induced reversal of antistereotypic and cataleptogenic effects of neuroleptics in rats. Acta Pharmacologica et Toxicologica, 59: 319-324.

4. Silva SR, Futuro-Neto HA \& Pires JGP (1990). Inhibition of chlorpromazine-induced catalepsy by the $5-\mathrm{HT}_{1 \mathrm{~A}}$ ligands pindolol and buspirone in mice. Brazilian Journal of Medical and Biological Research, 23: 869-871.

5. Pires JGP, Ramage AG, Silva SR \& Futuro-Neto HA (1993). Effects of the 5-HT receptor antagonists cyanopindolol, ICI 169,369 , cisapride and granisetron on neuroleptic-induced catalepsy in mice. Brazilian Journal of Medical and Biological Research, 26: 847-852.

6. Silva SR, Futuro-Neto HA \& Pires JGP (1995). Effects of $5-\mathrm{HT}_{3}$ receptor antagonists on neuroleptic-induced catalepsy in mice. Neuropharmacology, 34: 97-99.

7. Pires JGP, Silva SR \& Futuro-Neto HA (1996). Effects of losartan on neurolepticinduced catalepsy in mice. Brazilian Journal of Medical and Biological Research, 29: 1045-1047.

8. Perry KW \& Fuller RW (1992). Systemic administration of fluoxetine does not increase levels of dopamine in the striatum. Life Sciences, 50: 1683-1690.

9. Garthwaite J \& Boulton CL (1995). Nitric oxide signalling in the central nervous system. Annual Review of Physiology, 57: 683-706.

10. Hoffman BJ, Miller KJ \& Gould LM (1994). New perspectives on signal transmission: the serotonin transporter. 3rd IUPHAR Satellite Meeting on Serotonin, Chicago, USA, 10 (Abstract).

11. Feelisch $M$ (1991). The biochemical pathways of nitric oxide formation from nitrovasodilators: Appropriate choice of exogenous NO donors and aspects of preparation and handling of aqueous NO solutions. Journal of Cardiovascular Pharmacology, 17: S25-S33.

12. Tassorelli C \& Joseph SA (1995). Systemic nitroglycerin induces Fos immunoreactivity in brainstem and forebrain structures of the rat. Brain Research, 682: 167-181.

13. Pires JGP, Domingues AL, Souza MT, Cardoso ALT, Silva SR \& Futuro-Neto HA (1996). The centrally active NO-donor, isosorbide dinitrate, attenuates the vagal bradycardia evoked by the Bezold-Jarisch reflex. Society for Neuroscience $A b$ stracts, 22 (Part 1): 634

14. Marras RA, Martins AP, Del Bel EA \& Guimarães FS (1995). L-NOARG, an inhibitor of nitric oxide synthase, induces catalepsy in mice. NeuroReport, 7: 158-160.

15. Stanford SC (1996). Prozac: panacea or puzzle? Trends in Pharmacological Sciences, 17: 150-154.

16. Silva MT, Rose $S$, Hindmarsh JG, Aislaitner G, Gorrod JW, Moore PK, Jenner P \& Marsden CD (1995). Increased striatal dopamine efflux in vivo following inhibition of cerebral nitric oxide synthase by the novel monosodium salt of 7-nitro indazole. British Journal of Pharmacology, 114: 257-258

17. Meltzer HY, Young M, Metz J, Fang VS, Schyve PM \& Arora RC (1979). Extrapyramidal side effects and increased serum prolactin following fluoxetine, a new antidepressant. Journal of Neural Transmission, 45: 165-175. 